\title{
Análise Preliminar dos Processos Ético- -Disciplinares transitados em julgado no Cofen (2005-2010): um ensaio para a pesquisa
}

\author{
Linconl Uchoa Sidon \\ Ivete Santos Barreto² \\ Osvaldo Albuquerque Sousa Filho ${ }^{3}$ \\ Fabrício Macedo ${ }^{4}$ \\ Alexandre Dias Peixoto 5
}

\section{INTRODUÇÃO}

U ma infração ética consiste na ação, omissão ou conivência que implique desobediência e/ou inobservância às disposições previstas no Código de Ética dos profissionais de Enfermagem (CEPE). Assim, o agir culposo, ou seja, sem a intenção de causar dano a outrem, pode resultar em algum tipo de risco ou dano ao paciente quando comprovada a negligência, imperícia ou imprudência do profissional( ${ }^{(1,2)}$.

Nessa perspectiva, um número relevante de Processos Ético-Disciplinares (PED) tem sido instaurado pelas mais diversas razões e, possivelmente, com diferentes julgamentos no Sistema Cofen/ Conselhos Regionais de Enfermagem, desde a sua criação $(3,4,5,6)$.

Apesar da importância do tema para o avanço da Enfermagem no Brasil, ainda são escassos os estudos que caracterizam a dimensão desses PED no País, bem como o perfil das infrações éticas cometidas e dos profissionais de enfermagem envolvidos em relação aos PED tramitados em julgado no Sistema Cofen/ Conselhos Regionais de Enfermagem.

Partindo-se dessa premissa, a presidente do Cofen, Dra Marcia Cristina Krempel, instituiu o Grupo de Trabalho de Processos Ético-Disciplinares, com a finalidade de coletar e analisar os dados provenientes de PED tramitados no Cofen nos últimos 10 anos. Este primeiro relatório também visa despertar a atenção dos leitores quanto à pesquisa em tela, revelando a importância das ações desenvolvidas pelos demais grupos de trabalho existentes no Cofen.

A pesquisa foi planejada e iniciada no mês de julho de 2012, com objetivo preliminar de localizar, identificar e registrar todos os PED transitados em julgado no Cofen no período de 2000 a 2011. Essas etapas antecederam a coleta de dados, com base nas prerrogativas de uma pesquisa documental.

Resultados Preliminares - A primeira análise retrospectiva realizada com base nos PED transitados em julgado disponíveis no Cofen para o período de 2005 a 2010 possibilitou constatar que 185 PED foram tramitados no Cofen, gerando uma média aproximada de 31 PED recebidos para julgamento por ano. Nesse quinquênio, os processos foram provenientes de 21 Conselhos Regionais de Enfermagem (Coren), com destaque ao Coren São Paulo (25,9\%),
Minas Gerais (18,4\%) e Rio Grande do Sul (16,2\%), responsáveis por $60,5 \%$ dos PED recebidos no Cofen, conforme descrito no livro de protocolo de recebimentos utilizado pela Secretaria Geral do Cofen, responsável pela gestão dos PED no Cofen (Tabela 1).

Ao aprofundar a análise entre os PED transitados em julgado no triênio 2008 a 2010 (Tabela 1), observou-se que entre os 107 PED disponíveis no Cofen, 29,0\% (31) foram devolvidos aos Conselhos Regionais de origem por falhas de instrução processual, que ensejaram em nulidade, arquivamento e/ou solicitação de correção dos atos processuais, possivelmente por inobservância dos trâmites legais.

Ao pesquisar o perfil dos profissionais de Enfermagem envolvidos nesses PED, observou-se que dos 117 denunciados, 53,9\% (63) são enfermeiros, 33,3\% (39) auxiliares de enfermagem, 19,7\% (23) técnicos de enfermagem e 1,7\% (2) são atendentes de enfermagem.

Em relação às penalidades aplicadas entre os PED transitados em julgado no triênio, contatou-se que para $8,6 \%$ (10) dos profissionais de Enfermagem denunciados aplicou-se a penalidade de advertência verbal, 15,4\% (18) receberam a penalidade de censura, $10,3 \%$ (12) foram penalizados com multas, $6,0 \%$ (7) foram suspensos de suas atividades, $6,9 \%$ (8) receberam a penalidade de cassação ao direito do exercício profissional e $27,4 \%$ (32) foram absolvidos da denúncia. Foram excluídos desses cálculos os denunciados relacionados entre os PED devolvidos ou arquivados.

As variações quantitativas observadas na distribuição anual dos PED encaminhados pelos Conselhos Regionais ao Cofen parecem refletir o número de profissionais de Enfermagem registrados em cada Unidade Federada e, sobretudo, a dinâmica e complexidade do processo de trabalho na Enfermagem.

Além disso, outros fatores devem ser levados em consideração, tais como: o quantitativo de denúncias, recebidas e apuradas, em cada um dos 27 Conselhos Regionais de Enfermagem, bem como as possíveis falhas nas atividades administrativas relacionadas à condução dos PED, haja vista que estes podem prescrever por falta de julgamento(7). Essas situações podem representar os motivos pelos quais cinco Conselhos Regionais não encaminharam ou motivaram qualquer PED para julgamento junto ao Cofen (Tabela 1).

1 Enfermeiro. Mestre em Saúde Pública. Coordenador do Grupo de Trabalho de Processos Ético-Disciplinares/Cofen.

2 Enfermeira. Mestre em Ciências da Saúde. Conselheira Federal, Membro do Grupo de Trabalho de Processos Ético-Disciplinares/Cofen.

3 Enfermeiro. Mestre em Educação em Saúde. Vice-Presidente do Cofen. Membro do Grupo de Trabalho de Processos Ético-Disciplinares/Cofen.

4 Advogado. Especialista em Direito Público. Assessor Legislativo do Cofen; Membro do Grupo de Trabalho de Processos Ético-Disciplinares/Cofen.

5 Técnico Administrativo. Responsável pelo Setor de Processos Éticos do Cofen. Colaborador do Grupo de Trabalho de Processos Ético-Disciplinares/Cofen. 


\section{PROFISSIONAL DE ENFERMAGEM:}

\section{O COFEN LANÇOU SEU NOVO PORTAL COFEN, MAIS INTERATIVO E DINÂMICO PARA VOCÊ.}

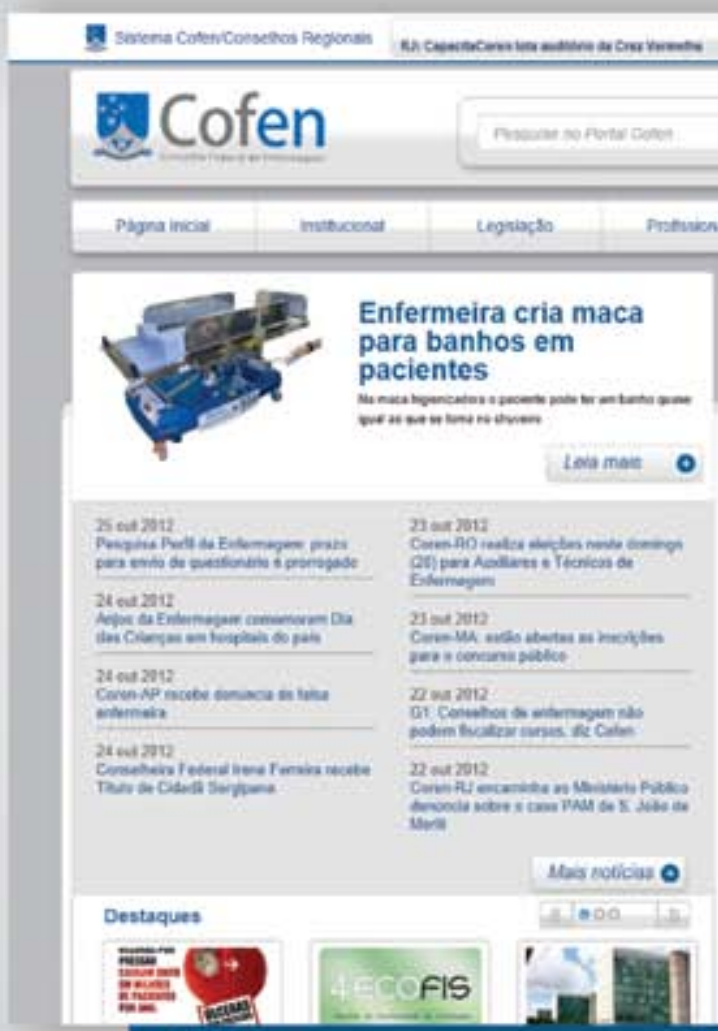

Flickr

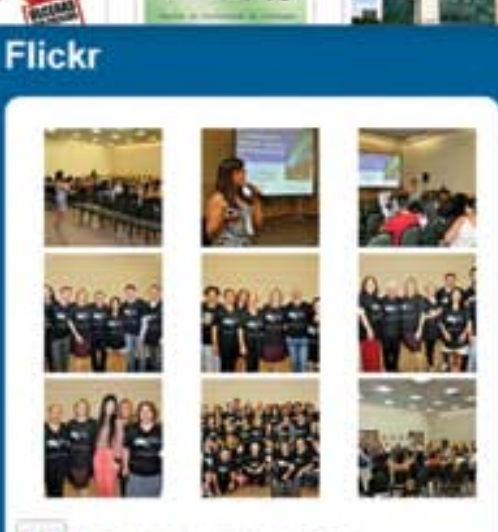

-e Weja pajgina do Cofen no Flick
Facebook

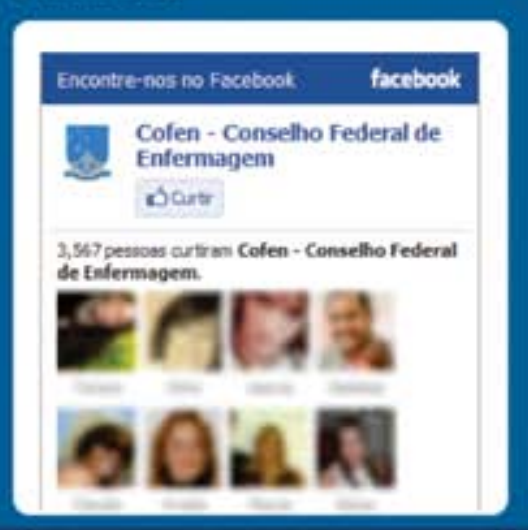

DESTAQUES DO NOVO PORTAL.

NOVA MARCA

PORTAL DE EMPREGOS REDES SOCIAIS LEGISLAÇÃO RÁPIDA +NOTÍCIAS

Refis2012

Fotos

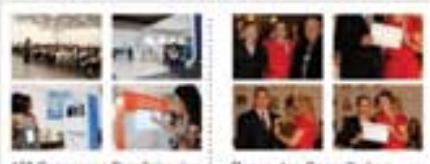

powatis

\section{Twitter}

D2 about a day ago Cofen disse: Fantistico apresentou apenas 10 segundos de uma ionais de eafermagem. migre.me/bgRe?

E. about 4 days ago Coten disse: Noca: Oeorrvacia de erros eavolvendo profissionais de Enfermagema no Rio de Janeiro - nowo.portalcofen. gon.br/nota-ocorrenci-

27. about 6 days ago Coten disse: Coten realina Treinamento em Processos Éticos para Conselheiros Repionais nowo. portalcofen. govibe coten-realin.

20. about 13 days aso Cofen disse: Ministério da Saude vai analiar o uso e o acesso aos nemidios.

sovo.portaloofen.sov.br/pesquisa-nacio.

Onovo Portal Cofen traz aos usuários novos recursos para buscas e facilidades para os profissionais de enfermagem como notícias, legislaçāo rápida, dúvidas frequentes, redes sociais, portal nacional de empregos, observatório parlamentare acesso do profissional. Acessee participe. 
Tabela 1 - Processos Éticos encaminhados para julgamento no Cofen, durante o período de 2005 a 2010

\begin{tabular}{|c|c|c|c|c|c|c|c|c|c|c|c|c|c|c|}
\hline \multicolumn{15}{|l|}{ Ano* } \\
\hline \multirow[b]{2}{*}{ COREN } & \multicolumn{2}{|c|}{2005} & \multicolumn{2}{|c|}{2006} & \multicolumn{2}{|c|}{2007} & \multicolumn{2}{|c|}{2008} & \multicolumn{2}{|c|}{2009} & \multicolumn{2}{|c|}{2010} & \multicolumn{2}{|c|}{ Total } \\
\hline & $\mathbf{N}$ & $\%$ & $\mathbf{N}$ & $\%$ & $\mathbf{N}$ & $\%$ & $\mathbf{N}$ & $\%$ & $\mathbf{N}$ & $\%$ & $\mathbf{N}$ & $\%$ & $\mathbf{N}$ & $\%$ \\
\hline São Paulo & 9 & 39,1 & 4 & 21,1 & 3 & 8,3 & 8 & 24,2 & 7 & 23,3 & 17 & 38,6 & 48 & 25,9 \\
\hline Paraná & 6 & 26,1 & 0 & 0,0 & 0 & 0,0 & 5 & 15,2 & 1 & 3,3 & 0 & 0,0 & 12 & 6,5 \\
\hline Distrito Federal & 2 & 8,7 & 2 & 10,5 & 4 & 11,1 & 1 & 3,0 & 4 & 13,3 & 1 & 2,3 & 14 & 7,6 \\
\hline Mato Grosso do Sul & 2 & 8,7 & 2 & 10,5 & 1 & 2,8 & 0 & 0,0 & 0 & 0,0 & 0 & 0,0 & 5 & 2,7 \\
\hline Minas Gerais & 1 & 4,3 & 4 & 21,1 & 9 & 25,0 & 7 & 21,2 & 5 & 16,7 & 8 & 18,2 & 34 & 18,4 \\
\hline Rio Grande do Sul & 1 & 4,3 & 3 & 15,8 & 10 & 27,8 & 3 & 9,1 & 4 & 13,3 & 9 & 20,5 & 30 & 16,2 \\
\hline Rondônia & 1 & 4,3 & 0 & 0,0 & 0 & 0,0 & 0 & 0,0 & 2 & 6,7 & 0 & 0,0 & 3 & 1,6 \\
\hline Santa Catarina & 1 & 4,3 & 1 & 5,3 & 3 & 8,3 & 1 & 3,0 & 0 & 0,0 & 0 & 0,0 & 6 & 3,2 \\
\hline Amapá & 0 & 0,0 & 1 & 5,3 & 0 & 0,0 & 0 & 0,0 & 0 & 0,0 & 0 & 0,0 & 1 & 0,5 \\
\hline Bahia & 0 & 0,0 & 0 & 0,0 & 0 & 0,0 & 1 & 3,0 & 0 & 0,0 & 0 & 0,0 & 1 & 0,5 \\
\hline Ceará & 0 & 0,0 & 1 & 5,3 & 0 & 0,0 & 0 & 0,0 & 0 & 0,0 & 0 & 0,0 & 1 & 0,5 \\
\hline Espírito Santo & 0 & 0,0 & 0 & 0,0 & 1 & 2,8 & 1 & 3,0 & 0 & 0,0 & 2 & 4,5 & 4 & 2,2 \\
\hline Goiás & 0 & 0,0 & 0 & 0,0 & 1 & 2,8 & 0 & 0,0 & 1 & 3,3 & 0 & 0,0 & 2 & 1,1 \\
\hline Mato Grosso & 0 & 0,0 & 0 & 0,0 & 1 & 2,8 & 0 & 0,0 & 0 & 0,0 & 0 & 0,0 & 1 & 0,5 \\
\hline Pará & 0 & 0,0 & 0 & 0,0 & 0 & 0,0 & 0 & 0,0 & 0 & 0,0 & 1 & 2,3 & 1 & 0,5 \\
\hline Paraíba & 0 & 0,0 & 0 & 0,0 & 2 & 5,6 & 2 & 6,1 & 0 & 0,0 & 0 & 0,0 & 4 & 2,2 \\
\hline Pernambuco & 0 & 0,0 & 1 & 5,3 & 0 & 0,0 & 0 & 0,0 & 0 & 0,0 & 1 & 2,3 & 2 & 1,1 \\
\hline Piauí & 0 & 0,0 & 0 & 0,0 & 0 & 0,0 & 1 & 3,0 & 3 & 10,0 & 0 & 0,0 & 4 & 2,2 \\
\hline Rio de Janeiro & 0 & 0,0 & 0 & 0,0 & 1 & 2,8 & 2 & 6,1 & 2 & 6,7 & 4 & 9,1 & 9 & 4,9 \\
\hline Rio Grande do Norte & 0 & 0,0 & 0 & 0,0 & 0 & 0,0 & 1 & 3,0 & 0 & 0,0 & 1 & 2,3 & 2 & 1,1 \\
\hline Tocantins & 0 & 0,0 & 0 & 0,0 & 0 & 0,0 & 0 & 0,0 & 1 & 3,3 & 0 & 0,0 & 1 & 0,5 \\
\hline Total & 23 & 100,0 & 19 & 100,0 & 36 & 100,0 & 33 & 100,0 & 30 & 100,0 & 44 & 100,0 & 185 & 100,0 \\
\hline
\end{tabular}

Fonte: Conselho Federal de Enfermagem, 2012

*Ano de tramitação do PED no Cofen

OBS: Sergipe, Alagoas, Maranhão, Roraima, Acre e Amazonas não encaminharam PED ao Cofen no período.

As falhas no processo de gestão dos PED também podem representar custos desnecessários ao Sistema Cofen/Conselhos Regionais e partes envolvidas, denunciantes e denunciadas, além da sobrecarga de trabalho, ainda que normatizar, disciplinar e fiscalizar o exercício profissional seja sua principal finalidade ${ }^{(8)}$.

Vale ressaltar que os PED encaminhados ao Cofen não representam a dimensão ou uma amostra significativa de PED existentes em 1a instância. Essa observação sugere que a análise seja expandida aos Conselhos Regionais de Enfermagem a partir dos resultados encontrados gradualmente nesta pesquisa.

Os resultados apresentados são preliminares, mas já revelam importantes aspectos dos PED transitados em julgado no Cofen. Como o objetivo maior deste estudo é subsidiar políticas eficientes de conscientização, sensibilização e prevenção das infrações éticas entre os profissionais de Enfermagem, resultados mais amplos desta pesquisa serão fundamentais para que o Sistema Cofen/ Conselhos Regionais de Enfermagem se aproxime cada vez mais das reais necessidades da Enfermagem brasileira, oferecendo qualidade e infraestrutura para melhor atendimento ao público.

Para além da pesquisa, percebeu-se a necessidade de padronizar e sistematizar o processo de gestão administrativa dos PED no Sistema Cofen/Conselhos Regionais de Enfermagem, guardadas as particularidades e subjetividades do julgamento em qualquer das instâncias.

\section{Referências}

1. Oguisso T, Schmidt MJ. O exercício da enfermagem: uma abordagem éticolegal. São Paulo: Guanabara Koogan; 2010.

2. Oguisso T, Schmidt MJ, Freitas GF. Fundamentos éticos e morais na prática de enfermagem. Enferm Foco. 2010;1(3):104-8.

3. Freitas GF, Oguiso T, Merighi MAB. Motivações do agir de enfermeiros nas ocorrências éticas de enfermagem. Acta Paul Enferm. 2006;19(1):76-81. 4. Muzzi HM, Costa JA, Nunan RRM, Arashiro VBV. Conselho Regional de Enfermagem de Minas Gerais. Câmara Técnica de Avaliação, Acompanhamento e Controle de Processos Éticos. Processos éticos: um estudo sobre infraçōes. 2009:1-9. 5. Cortez E, Castro IMS, Sales JFA, Almeida PA, Silva PCU, Carmo TG. Aspectos éticos e implicações legais das infrações notificadas no Coren/RJ entre os anos de 2000 e 2005. Enferm Bras. 2007;6(6):364-72.

6. Mendes HWB, Caldas Jr. AL. Infraçöes éticas envolvendo pessoal de enfermagem. Rev Latinoam Enferm. 1999;7(5):5-14.

7. Conselho Federal de Enfermagem. Resolução nº. 370/2010. Aprova o Código de Processo Ético dos Conselhos de Enfermagem [Internet]. Disponível em: http://novo.portalcofen.gov.br/resoluo-cofen-n-3702010_6016.html. 8. Brasil. Lei no. 5.905, de 12 de julho de 1973. Dispõe sobre a criação dos Conselhos Federal e Regionais de Enfermagem e dá outras providências [Internet]. Disponível em: http://novo.portalcofen.gov.br/lei-n-590573-de-12de-julho-de-1973_4162.html. 


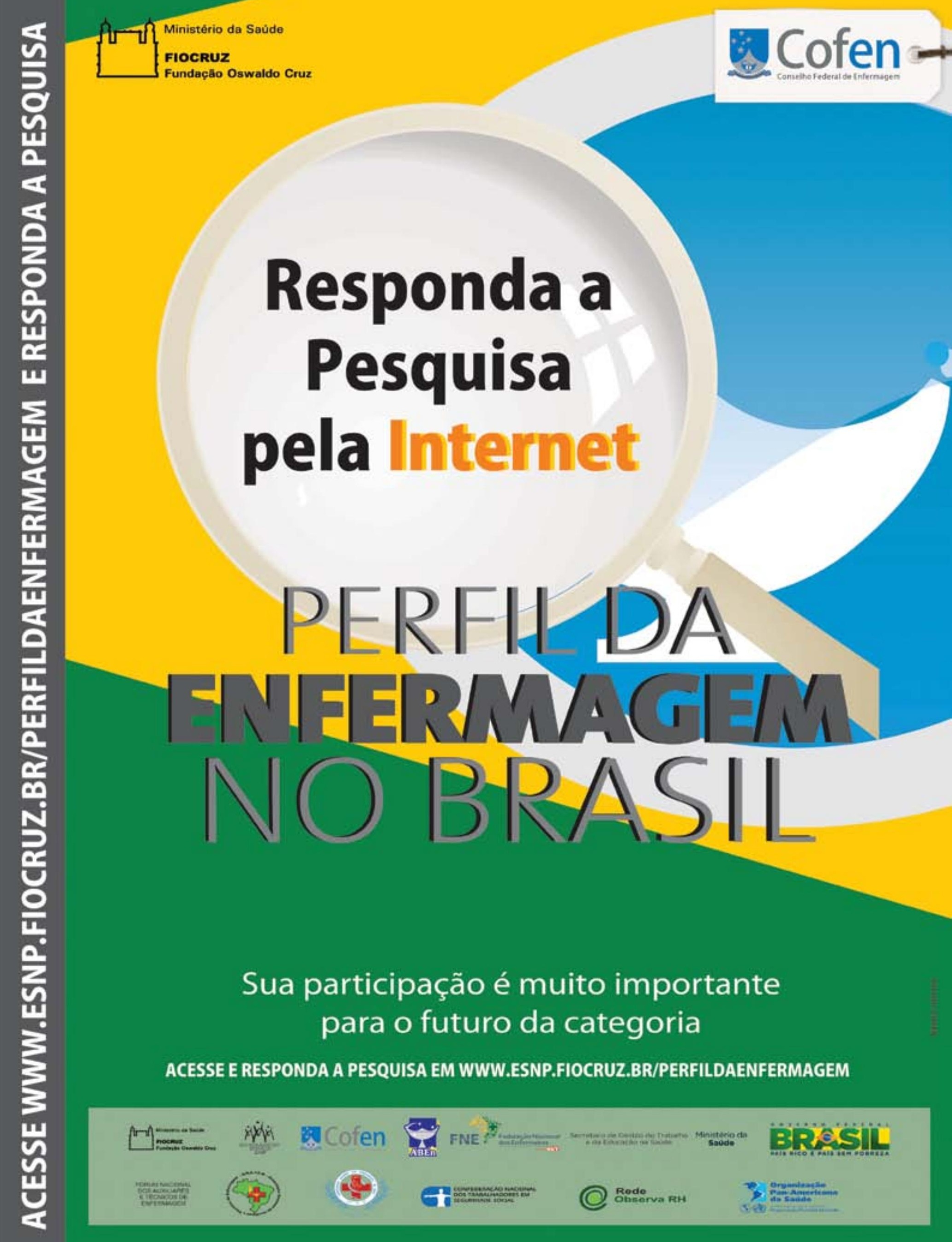

